Page 1 of 28

\title{
ANALYTICAL DETECTION AND BIOLOGICAL ASSAY OF ANTILEUKEMIC DRUG USING GOLD NANOPARTICLES
}

\author{
V. Selvaraj ${ }^{1}$, M. Alagar ${ }^{1, *}$ and I. Hamerton ${ }^{2}$ \\ ${ }^{1}$ Department of Chemical Engineering, Alagappa College of Technology, Anna University, \\ Chennai - 600 025, India \\ ${ }^{2}$ Chemistry Division, School of Biomedical and Molecular Sciences, University of Surrey, \\ Guildford, Surrey, GU2 7XH, United Kingdom \\ * To whom correspondence should be addressed
}

\section{Introduction}

Materials in the nanometre size range may possess beneficial properties which can influence the development of remarkable industrial and engineering applications including biotechnological systems. The formation of hybrid systems comprising nanoparticles and biomolecules paves the way from cell markers to biosensing ${ }^{1,2}$, bioimaging ${ }^{3}$ and targeted drug delivery $^{4,5}$. Nanoparticles have been found to be useful in the development of systemic, oral, pulmonary, transdermal and other administration routes to study drug targeting, the enhancement of drug bioavailability and protection of drug bioactivity and stability ${ }^{6-8}$. For instance, nanoparticles can be used to enhance oral delivery, ${ }^{6,9}$ by improving the bioavailability of poorly absorbed drugs. They are able to penetrate the cells to facilitate cellular internalization and connective tissue permeation, thus enabling the drugs to be delivered efficiently to the targeted tissue without clogging capillaries ${ }^{10,11}$. Consequently, nanotechnology is now used as potential route to study the delivery of anti-leukaemic drugs and used to improve drug diffusion through the blood/brain barrier. Nanoparticles can also act as drug carriers during intravenous injection, which allows the carriers to penetrate the membranes of the cells and deliver the drugs to cancerous tomours. A recent literature review has indicated that some nanoparticle-bound antitumour agents showed prolonged drug retention in tumours, reduction in tumour growth and prolonged survival of tumour bearing animals ${ }^{12-15}$. Optical ${ }^{16}$ and electrochemical ${ }^{17}$ sensing of biomolecules using colloidal gold is widely studied by the conjugation of various biomolecules such as protein A, avidin, streptavidin, glucose oxidase, horseradish peroxidise and immunoglobins, etc.. 
Page 2 of 28

6-Mercaptopurine (6-MP) has achieved a special place in biomedicine, owing to its activity in cancer chemotherapy ${ }^{21}$. It is one of the oldest antineoplastic drug currently in use and as there is a good correlation between the drug's coordination chemistry (it contains sulphur and nitrogen donor sites with potential for binding at $N-1, N-3, N-7$ and $N-9$ ) and its chemotherapeutic activity, it has attracted much attention ${ }^{22-24}$. The activity of 6-MP on tumour cells is believed to be due to its ability to convert these into the corresponding ribosides. In order to suppress the undesirable side effects associated with anti-tumour drugs, metal-drug complexes are currently used as slow release prodrugs of 6-MP. The latter employ coordinated components of certain transition metals like platinum and palladium ${ }^{25}$. A number of detection methods have been suggested for the identification of 6-MP, which include potentiometric titration for tablet assay ${ }^{26}$, amperometric detection at a phthalocyanine-modified electrode ${ }^{27}$ and spectrophotometry ${ }^{28}$. Whilst Zima et al. ${ }^{29}$ reported the determination of 6-MP using tast polarography and differential pulse polarography at the dropping mercury electrode (DME), Basina et al. studied the electrochemical behaviour of 6MP using catalytic cathodic stripping voltammetry ${ }^{30}$ and found that 6-MP-modified mercury electrodes act as promoters for the redox exchange of Cytochrome C.

In the present work, gold nanoparticles have been used as probes for the detection of the anticancer drug 6-MP and evidence for their complexation has been obtained using UV-Visible spectroscopy, cyclic voltammetry, transmission electron microscopy (TEM), and fluorescent spectroscopy. Furthermore, the efficacy of the complexes of 6-MP and colloidal gold is examined with biological assays in order to evaluate their antibacterial and antifungal activities.

\section{Experimental}

\section{Apparatus}

Samples were characterized by ultraviolet (U.V.)-visible spectroscopy (Perkin-Elmer Lambda 25). The path length was $1 \mathrm{~cm}$ and matched $1 \times 1 \mathrm{~cm}^{2}$ cuvettes were used. Transmission electron microscopy (TEM) was undertaken employing a Tec NIE 10 instrument with an accelerating voltage of $120 \mathrm{kV}$; samples was prepared by mixing aqueous solution of MP (5mM) and gold solution $(1 \mathrm{mM})$. Fourier transform infrared (FTIR) spectroscopy was performed using a PE IR 
Page 3 of 28

SPECTRUM ASCII PEDS 1.60 spectrometer and samples were presented as $\mathrm{KBr}$ pellets. Spectra were acquired at room temperature at a resolution of $4 \mathrm{~cm}^{-1}$. Optical emission spectroscopy was carried out using Fluoromax-2, Gram 386 spectrometer. Cyclic voltammetric studies was performed using an Autolab PG Stat 12 electrochemical analyzer in a three electrode cell, using platinum wire as the counter electrode and a $50 \mathrm{mM} \mathrm{KCl}$ calomel reference electrode. The scans were initiated at $-0.4 \mathrm{~V}$ and all electrochemical measurements were performed in a static nitrogen atmosphere. The working electrode used in this work was indium-tin-oxide (ITO) coated with colloidal gold and this was prepared in the following manner. The ITO slides were cleaned thoroughly by ultrasonication in water, followed by acetone. The cleaned glass slides were immersed in a solution ( $2 \% \mathrm{v} / \mathrm{v})$ of 3-aminopropyl trimethoxysilane (APTMS) in methanol for 20 hours and subsequently immersed in freshly prepared colloidal gold for another 15 hours to create a submonolayer of gold nanoparticles. For electrode modification, freshly prepared gold plates were immersed for 12 hours in 6-MP solution (1 mM in $\left.0.01 \mathrm{M} \mathrm{HClO}_{4}\right)$, to avoid sulphide contamination. This process was repeated for all the electrochemical studies (Scheme 1).

\section{Insert Scheme 1}

\section{Materials}

$\mathrm{HAuCl}_{4} .3 \mathrm{H}_{2} \mathrm{O}(98 \%)$ and trisodium citrate (99 \%, AR) were purchased from CDH and Analytical Rasayan respectively. 6 -Mercaptopurine (6-MP) was synthesized according to a modified, previously reported procedure ${ }^{32,33}$ and the purity of the sample ascertained by comparing it with the commercial sample obtained from Aldrich. The reaction scheme is given below (Scheme.2)

\section{Insert Scheme 2}

\section{Synthesis of 6-chloropurine}

To phosphoryl chloride $\left(200 \mathrm{~cm}^{3}, 2.2 \mathrm{~mol}\right.$.) was added drop wise water $\left(20 \mathrm{~cm}^{3}\right)$ and, after all the water had been added, the mixture was boiled for 1.5 hours to dispel the hydrogen chloride. The mixture was subsequently cooled and the top layer was used for the chlorination of hypoxanthine to form 6-dichloropurine. A mixture of hypoxanthine $(8 \mathrm{~g})$ and pyrophosphoryl chloride $\left(64 \mathrm{~cm}^{3}\right)$ was heated in a sealed glass tube at $165^{\circ} \mathrm{C}$ for 19 hours. After cooling, the brown solution was 


\section{Page 4 of 28}

decanted from the solid residue in the tube and the volatile material was removed under reduced pressure. The syrupy residue was poured on to crushed ice (200 g), a small amount of tan precipitate removed and the filtrate was repeatedly extracted with portions of diethyl ether $(6 \times 350$ $\mathrm{cm}^{3}$ ). The ethereal solution was allowed to stand over anhydrous potassium carbonate for one hour and then over calcium sulphate overnight. On evaporation of diethyl ether, the crude product (4.3 g., $43 \%$ ), m.p. $175-177^{\circ} \mathrm{C}$, was obtained. A small portion was recrystallized from boiling water $\left(150 \mathrm{~cm}^{3}\right)$ and was allowed to stand at $0{ }^{\circ} \mathrm{C}$ for 1.5 hours and then filtered through a sintered glass funnel.

\section{Preparation of 6-mercaptopurine (6-MP)}

A suspension of 6-chloropurine $(0.98 \mathrm{~g}, 6.3 \mathrm{mmol}$.) and an equimolar quantity of thiourea in absolute ethanol $\left(14 \mathrm{~cm}^{3}\right)$ was heated to reflux; the solids dissolved and soon a yellow crystalline product precipitated. After refluxing for one hour, the mixture was chilled and crude 6-MP (0.64 g) was collected, the product was dried over $\mathrm{P}_{2} \mathrm{O}_{5}$ in vacuo at $100^{\circ} \mathrm{C}$.

\section{Preparation of citrate capped gold nanoparticles}

$\mathrm{HAuCl}_{4} \cdot 6 \mathrm{H}_{2} \mathrm{O}\left(1 \mathrm{mM}, 500 \mathrm{~cm}^{3}\right)$ was heated and to the boiling solution was added trisodium citrate (38.8 $\mathrm{mM}, 50 \mathrm{~cm}^{3}$ ) as one portion. After the addition, the previously yellow solution of gold chloride turned wine red in colour and gave a characteristic absorbance at $518 \mathrm{~nm}$ in the U.VVisible spectrum. From the TEM measurements, the average diameter of the gold nanoparticles was found to be in the range $17-18 \mathrm{~nm}$.

\section{Preparation of 6-mercaptopurine (6-MP) coated gold nanoparticles}

Citrate-stabilized gold nanoparticles $\left(1 \mathrm{mM}, 50 \mathrm{~cm}^{3}\right)$ were mixed with 6-MP $(5 \mathrm{mM})$ in 2-propanol $\left(25 \mathrm{~cm}^{3}\right)$ and stirred effectively for 5 hours until the wine red colour became blue. The 6-MP coated gold nanoparticles were obtained after centrifugation.

\section{Details of Microbial Assay}

Antibacterial and antifungal activities were studied using a disk diffusion method, wherein a suspension of both gramme positive and gramme negative organisms were added to sterile nutrient 
agar at $45{ }^{\circ} \mathrm{C}$ and the mixture was solidified on a Petri dish. Disks made from filter paper dipped in 6-MP and 6-MP-gold were placed on agar plates and the plates were left for one hour at $25{ }^{\circ} \mathrm{C}$ to allow a period of pre-incubation diffusion in order to minimize the effects of variation in time between the applications of different solutions. The plates were again incubated, this time at $37{ }^{\circ} \mathrm{C}$ for 24 hours, and observed for antibacterial activity by determining the diameters of the zones of inhibition for each of the samples.

\section{Results and Discussion}

The plasmon band observed for the wine red colloidal gold at $518 \mathrm{~nm}$ in the U.V-Visible spectrum is characteristic of gold nanoparticles. Pure drug shows a maxima at $321 \mathrm{~nm}$ The addition of 6-MP to colloidal gold results in a reduction in the intensity of this absorption band at $518 \mathrm{~nm}$ and 321 $\mathrm{nm}$ corresponding to $\mathrm{Au}(0)$ and drug moiety and is accompanied by the emergence of an additional peak at $670 \mathrm{~nm}$ (Figure 1).

\section{Insert Figure 1}

The latter can be verified by a colour change from purple to blue with the addition of drug to colloidal gold. The time dependent UV-Visible spectra were obtained after mixing (0.5 mM) 6MP with gold nanoparticles at timed interval of 30 minutes (curves a-d); curve (e) was obtained after 5 hours. The appearance of a new peak is due to the aggregation of gold nanoparticles and the replacement of citrate by 6-MP leading to the formation of gold-drug complex.

These observations are in agreement with the data obtained using FT-IR spectroscopy. 6-MP exists as tautomer form in the solid state as $\mathrm{C}=\mathrm{S}$ group and the IR spectrum of free (uncomplexed) 6-MP (Figure 2) displays absorption bands at $1275 \mathrm{~cm}^{-1}$ due the presence of the $\mathrm{C}=\mathrm{S}$ group.

\section{Insert Figure 2}

This peak was absent in the spectrum of the adsorbed form (Figure 3) apparently confirming the existence of complex formation of the 6-MP through the sulphur atom. 
Page 6 of 28

\section{Insert Figure 3}

Fluorescence studies were also undertaken to ascertain the binding of the drug moiety with the gold nanoparticles. Thus, free 6-MP has a broad emission centred at $c a$. $380 \mathrm{~nm}$ when excited at a wavelength of $320 \mathrm{~nm}$. The non-fluorescent gold nanoparticles are transformed into a markedly fluorescent species when added to 6-MP, the intensity of fluorescence being decreased when colloidal gold is added to the drug (Figure 4).

\section{Insert Figure 4}

\section{Insert Figure 5}

The fluorescence spectrum of 6-MP was studied with different concentrations of gold nanoparticles (Figure 6).

\section{Insert Figure 6}

With a gradual increase in concentration of $\mathrm{Au}(0)$, (Figure 6b-e), the intensity of 6-MP (Figure 6) decreases concomitantly. Throughout this experiment the concentration of 6-MP remained constant and displayed peaks at $424 \mathrm{~nm}$ and $368 \mathrm{~nm}$ in the emission and excitation spectra respectively. Cyclic voltammetry (cv) was employed using gold nanoparticle-modified electrodes, to ascertain the nature of the bond formation and the cyclic voltammograms of the gold nanoparticle-modified ITO plate immersed in $0.01 \mathrm{M} \mathrm{HClO}_{4}$ solutions are shown (Figure 7). The scans were initiated at $-0.4 \mathrm{~V}$ and a reduction peak was observed at $+0.69 \mathrm{~V}$, which corresponds to the formation of gold oxide.

\section{Insert Figure 7}

The electrochemical evaluation of 6-MP capped gold nanoparticles is also shown in Figure 7b. Peak 1 shows the $\mathrm{cv}$ response for the ITO electrode (modified with gold nanoparticles) in $1 \mathrm{mM}$ $\mathrm{K}_{4} \mathrm{Fe}(\mathrm{CN})_{6}$ at a scan rate of $10 \mathrm{mv} / \mathrm{s}$. After the exposure of gold electrode in the 6-MP solution, a 


\section{Page 7 of 28}

reduction in the peak current is observed due to the binding of 6-MP with the nanoparticles and more pronounced changes in the electrochemical profile of the gold electrode occur as the 6-MP concentration increases (Figure 7b). In fact, the onset of gold oxide formation is heralded by the change to a positive potential, indicating that the 6-MP molecule has been spontaneously adsorbed on the gold surface. However at more positive potentials, a large anodic current was obtained, which should correspond to the oxidative desorption of the previously adsorbed molecule ${ }^{35}$, and a reduction peak was absent when the gold electrode surface was completely adsorbed by 6-MP. The shape of the voltammograms for $\left[\mathrm{Fe}(\mathrm{CN})_{6}\right]^{3-}$ and $\left[\mathrm{Fe}(\mathrm{CN})_{6}\right]^{4-}$ at the coated and uncoated substrates indicates that the current is primarily controlled by linear diffusion and suggest that the monolayer does not completely block electron transfer, as these small molecules provide only a partial barrier. This decrease in both anodic and cothodic current is due to blocking behaviour of MP on gold modified electrode (Scheme 3).

\section{Insert Scheme 3}

The TEM image (Figure 8) displays clearly aggregates of gold nanoparticles: colloidal gold has an average diameter of $c a .18 \mathrm{~nm}$. On the addition of gold, aggregation of the gold takes place (this phenomenon was previously illustrated in Schemes 2 and 3).

\section{Insert Figure 8}

\section{Determination of the antibacterial and antifungal activity of the 6-MP-colloidal gold complex}

Table 1 details the growth inhibition effected by drug-coated gold nanoparticles against both gramme positive and gramme negative organisms viz Micrococcus luteus, Staphylococcus aureus, Pseudomonas aeruginosa and E-Coli. It was observed that the coated colloid was most effective for gramme negative organisms and the levels of inhibition can be seen clearly in Figure 9.

Figure 9 Antibacterial activity of 6-MP and 6-MP-covered gold. (a) Micrococcus luteus (b) Staphylococcus luteus (c) E-Coli (d) Staphylococcus aureus 
Table 1 Antibacterial activity of 6-mercaptopurine (6-MP)

\begin{tabular}{|c|c|c|c|}
\hline \multirow{2}{*}{ Micro organisms } & \multirow{2}{*}{ Nature of organism } & \multicolumn{2}{|c|}{ Levels of Zone of inhibition } \\
\cline { 3 - 4 } & & Pure 6-MP & $\begin{array}{c}\text { 6-MP-coated gold } \\
\text { nanoparticles }\end{array}$ \\
\hline Micrococcus luteus & Gramme Positive & 41 & 45 \\
\hline Staphylococcus aureus & Gramme Positive & 49 & 57 \\
\hline Pseudomonas aeruginosa & Gramme Negative & 51 & 63 \\
\hline E-Coli & Gramme Negative & 60 & 72 \\
\hline
\end{tabular}

6-MP also shows a good antifungal activity against Aspergillus fumigatus and Aspergillus niger and these activity levels were found to be enhanced on the addition of colloidal gold (Table 2 and Figure 10). The colloidal gold solution alone does not show any appreciable antifungal and antibacterial activities.

\section{Insert Figure 10}

Table 2 Antifungal activity of 6-mercaptopurine (6-MP)

\begin{tabular}{|c|c|c|}
\hline \multirow{2}{*}{ Fungal Organisms } & \multicolumn{2}{|c|}{ Levels of Zone of inhibition } \\
\cline { 2 - 3 } & Pure 6-MP & 6-MP-coated gold nanoparticles \\
\hline Aspergillus fumigatus & 45 & 59 \\
\hline Aspergillus niger & 32 & 37 \\
\hline
\end{tabular}

Although these preliminary studies demonstrate the effectiveness of the gold-drug complex, the precise mechanism by which it operates is not yet known and work continues to investigate this further. Some gold-drugs, namely aurothiomalate and aurothioglucose, have already been evaluated for activity against human immunodeficiency virus (HIV) for the treatment of AIDS ${ }^{44,45}$ and, in the same way, gold-drugs have been explored for their effectiveness as antifungal, antibacterial and anticancer agents. Gold-drugs are used more as last-line modes of treatment for severe cases of rheumatoid arthritis in favour of organic drugs. It gives more potent and reduced toxic side effects. These properties may be due to geomentry of the complex. The normal mode of 
Page 9 of 28

metabolite pathway and the release mechanism may be altered (favourably in some cases) by the presence of metal nanoparticles, to attain a greater efficiency and reduced side effects.

\section{Conclusions}

The binding of 6-mercaptopurine (6-MP) to colloidal gold via complexation through the thiol group was studied using different analytical techniques (e.g. U.V-Visible spectroscopy, cyclic voltammetry, transmission electron microscopy, fluorescence spectroscopy and IR spectroscopy). Fluorescence and electrochemical studies have shown the nature of interaction and will be used in future studies. The combination of gold with 6-MP results in a more potent complex compared with the individual parts.

\section{Acknowledgement}

The authors thank Dr Brendan J. Howlin (Chemistry Division, University of Surrey) for useful discussions in the preparation of this manuscript.

\section{References}

1. Bruchez M Jr, Moronne M, Gin P, Weiss S; Alivistas AP. Science 1998;281:2013-2016

2. Lahav M, Shipway AN, Willner, I. J Chem Soc Perkin Trans 2 1999;1925-1931

3. Djalali R, Chen Y, Matsui, H. J Am Chem Soc 2002;124:13660-13661

4. West JL, Halas NJ. Curr Opin Biotechnol 2000;11:215-217

5. Hermanson GT, editor. Bioconjugate Techniques. Academic Press: San Diego, 1996

6. Maincent P, Le Verge R, Sade P, Couvreur P, Devissaguet JP. J Pharm Sci 1986;75:955-958

7. Zeltner TB, Sweeney TD, Skornik WA, Feldman HA, Brain JD. J Appl Physiol 1991;70:11371145

8. Cappel MJ, Kreuter J. J Microencapsul 1991;8:369-374

9. Brannon-Peppas L. Int J Pharm 1995;116:1-9

10. Couvreur P, Tulkens P, Roland M, Trouet A, Speiser I. FEBS Lett 1997;84(2):323-326 
Page 10 of 28

11. Astier A, Doat B, Ferrer MJ, Benoit G, Fleury J, Rolland A, Leverge R. Cancer Res 1998;48:1835-1841

12. Beck P, Kreuter J, Reszka R, Fichtner I. J Microencapsul 1993;10:101-114

13. Simeonova M, Ilarionova M, Ivanova T, Konstantinov C, Todorov D. Acta Physiol Pharmacol Bulg 1991;17:43-49

14. Bennis S, Chapey C, Couvreur P, Robert J. Eur J Cancer 1994;30A:89-93

15. Verdun C, Brasseur F, Vranokx H, Couvreur P, Roland M. Cancer Chemother Pharmacol $1990 ; 26: 13-18$

16. Nath N, Chilkoti A. Anal Chem 2002;74:504-509

17. Raj CR, Okajima T, Ohsaka TJ. Electroanal Chem 2003;593:127-133

18. Saxena V, Sadoqi M, Kumar S, Shao J. SPIE’s OeMagazine;September 2004:21-23

19. Jalil R, Nixon JR. J Microencapsul 1990;7:297-325

20. Mu L, Feng SS. J Controlled Release 2003;86:33-48

21. Bostrom B, Evdmann G. Am J Pediatr Hematol Oncol 1993;15:80

22. Innocenti T. Cancer Chemother Pharmacol 1999;43:133

23. Drerievr, J.; Clin. Chem. (1998) 44, 2511

24. Mi, T. J. Controlled Release (1997) 44, 19

25. Chalmers, A. H.; Burdorf, T.; Murray, A. W. Biochem. Pharmacol. (1972) 21, 2662

26. Nikolic, K.; Velasavic, K. Mikrochim. Acta (1990) 1, 69

27. Chalmers, A. H. Biochem. Med. (1975) 12, 234

28. Harber, M.; Maddocks, J. Chromatogr. (1974) 101, 231

29. Barek, J.; Berka, A.; Dempiirova, L.; Zima, J. Collect. Czech. Chem. Commun. (1986) 51, 2466 
Page 11 of 28

30. Banica, I. A.; Gabriel, F.; Contantin, L. Electroanal. (1997) 9, 945

31. Hayat, A. (Ed.) Colloidal Gold: Principles, Methods and Applications. Academic Press: San Diego (1989) Vols 1-3

32. Elion, G. B.; Hitching, G. H. J. Am. Chem. Soc. (1956) 78, 3508-3510

33. A.Bendish,P.J,Russell.,JR; Fox, J. J.; J. Am. Chem. Soc.(1954) 76,6077

34. Yang, D. F.; Al-Mazna, H.; Morin, M. J. Phys. Chem. (1997) 101,1158

35. Eddowes, M. J.; Hill, H. A. O. J. Am. Chem. Soc. (1979) 101, 4461

36. (a) Eddowes, M. J.; Hill, H.A.O.; Uosaki, K. J. Am. Chem. Soc. (1979) 101, 7113; (b) Eddowes, M. J.; Hill, H.A.O.; Uosaki, K. Bioelectrochem. Bioenerg. (1980) 7, 527; (c) Albery, W. J.; Eddowes, M. J.; Hill, H. A. O.; Hillman, A.R. J. Am. Chem. Soc. (1981) 103, 3904.

37. Taniguchi, I.; Murakami, T.; Toyosawa, K.; Yamaguchi, H.; Yasukouchi, K. J. Electronal. Chem. (1982) 131, 397

38. (a) Taniguchi, I; Toyosawa, K.; Yamaguchi, H. J. Electroanal. Chem. (1982) 140, 187; (b) Taniguchi, I; Toyosawa, K.; Yamaguchi, H. J. Chem. Soc. Chem. Commun. (1982) 1032

39. Kadish, K. M. (Ed.) Electrochemical and spectrochemical studies of biological redox components, Adv. Chem. Ser., Vol. 201, American Chemical Society: Washington, D.C. (1982) Chapters. 7-9 and references cited therein

40. (a) Betso, S.-R.; Klapper, M. H.; Anderson, L. B. J. Am. Chem. Soc. (1972) 94, 8197; (b) Tarasevich, M.-R.; Bogdanovskaya, V.-A. Bioelectrochem. Bioenerg. (1976) 3, 589; (c) Cotton, T. M.; Schultz, S. G.; van Duyne, R. P. J. Am. Chem. Soc. (1980) 102, 7960; (d) Haladjian, J.; Bianco, P.; Serre, P.-A. J. Electroanal. Chem. (1980) 106, 397

41. Busby, C. C. and Creighton J. A., J. Electroanal. Chem. (1982) 140, 379

42. Okada, T.; Patterson, B. K.; Ye, S.-Q.; Gurney, M. E. Virology (1993) 192, 631 
Page 12 of 28

43. Yamaguchi, K.; Ushijima, H.; Hisano, M.; Inoue, Y.; Shimamura, T.; Hirano, T.; Muller, E. G. W. Microbiol. Immunol. (2001) 45, 549. 
Page 13 of 28

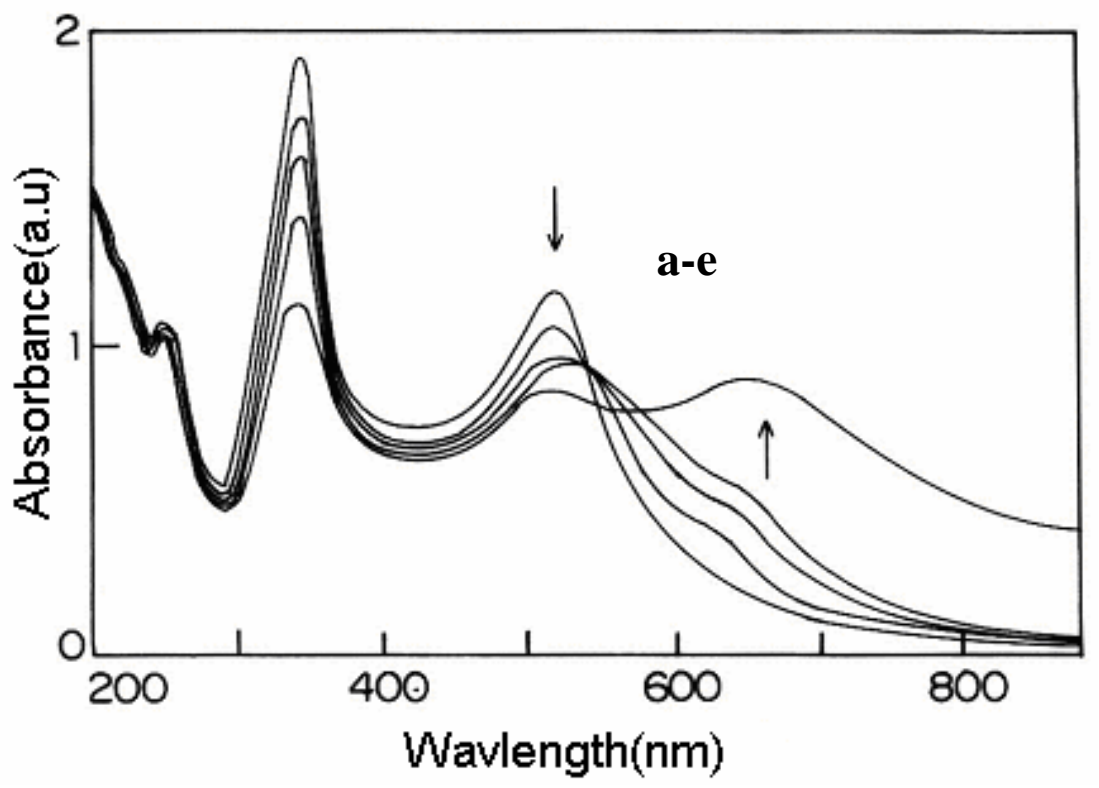

Figure 1 The time dependent UV-Visible obtained after mixing $(0.5 \mathrm{mM})$ 6-mercaptopurine with gold nanoparticles at time intervals of 30 minutes 
Page 14 of 28

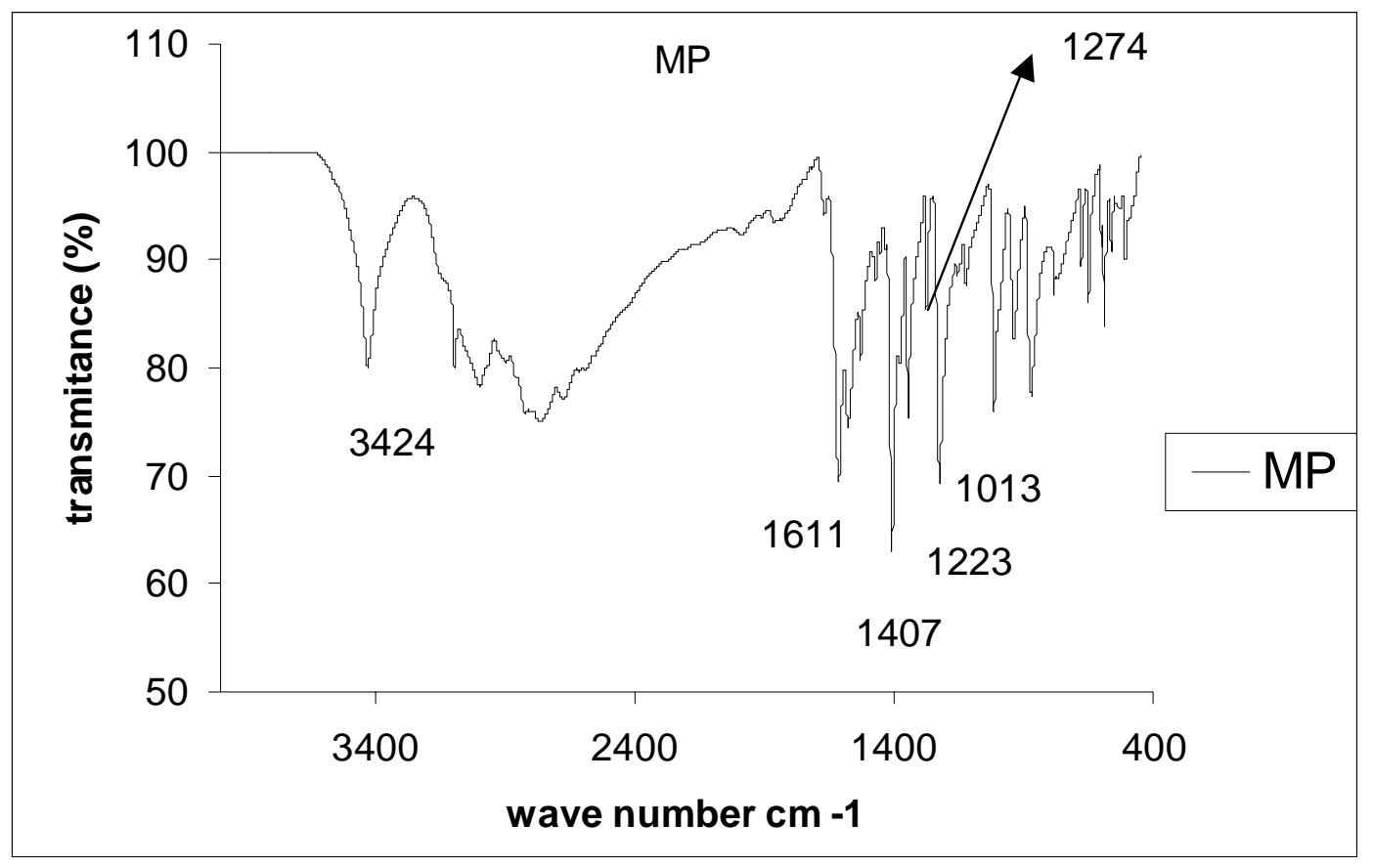

Figure 2 FTIR transmission spectrum of pure 6-mercaptopurine (6-MP) 
Page 15 of 28

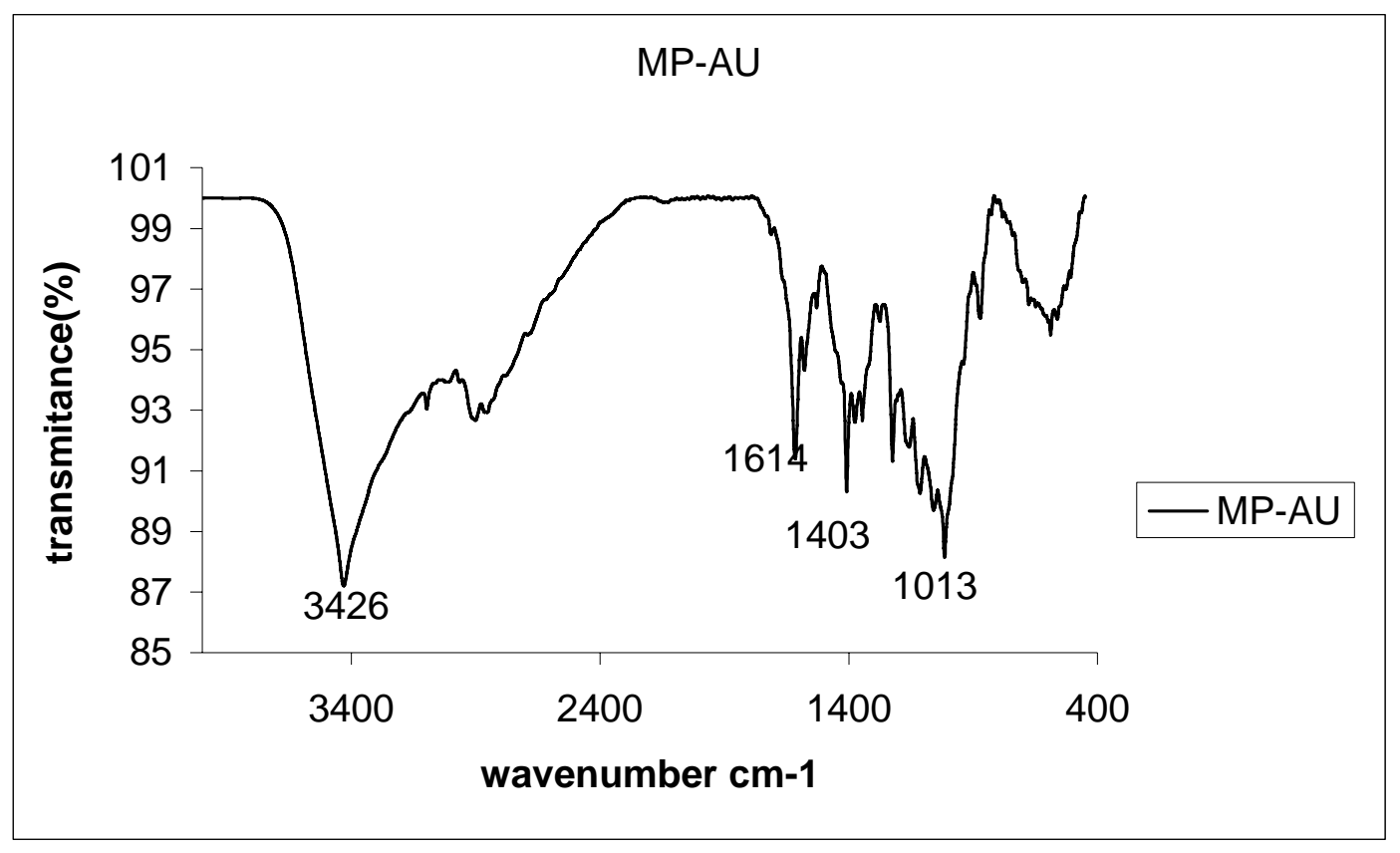

Figure 3 FTIR transmission spectrum of 6-MP with gold nanoparticles (MP-AU) 
Page 16 of 28

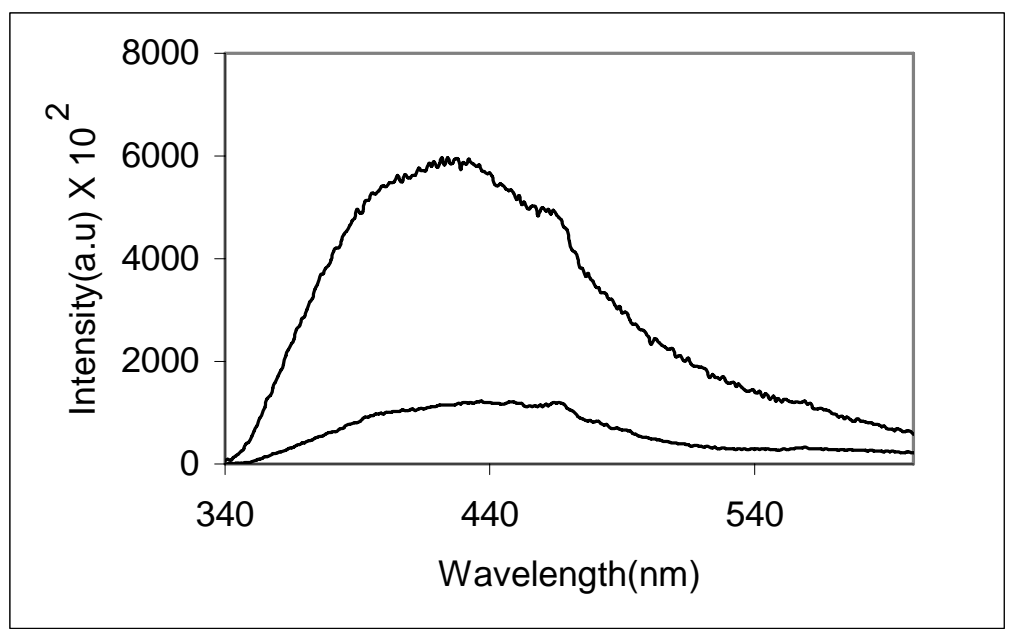

Figure 4 Emission spectra of (a) free 6-MP (5 mM) and (b) the adsorbed species on gold (1 mM, $0.5 \mathrm{~cm}^{3}$ ) nanoparticles taken in aqueous medium at intervals of $30 \mathrm{~min}$. 
Page 17 of 28

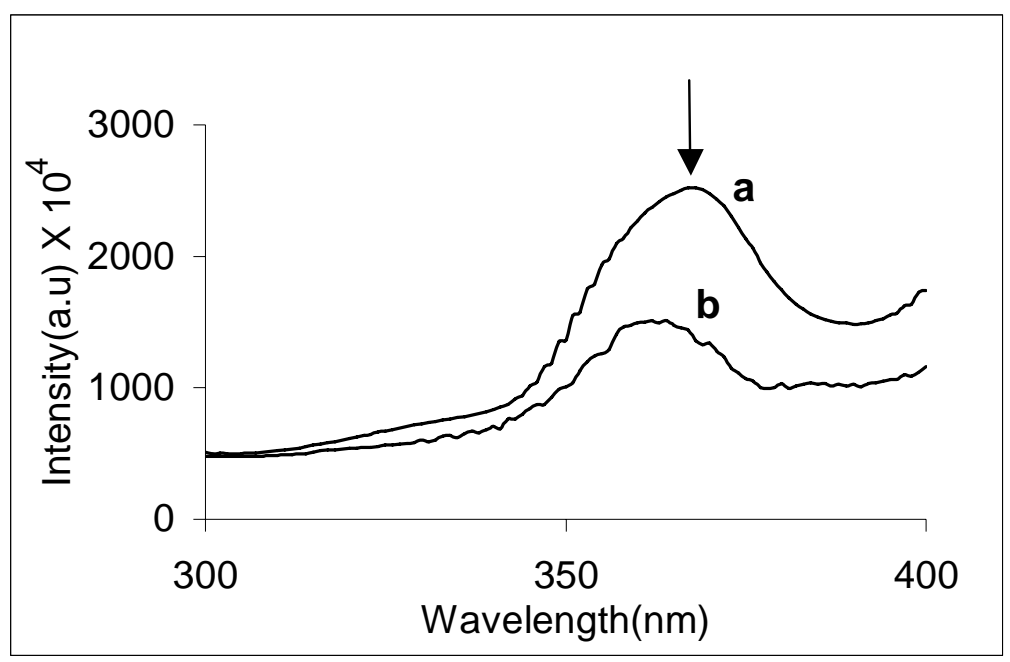

Figure 5 Excitation spectra taken in aqueous medium for (a) free 6-MP (5 mM) and (b) the adsorbed species on gold nanoparticles (1 mM) 
Page 18 of 28

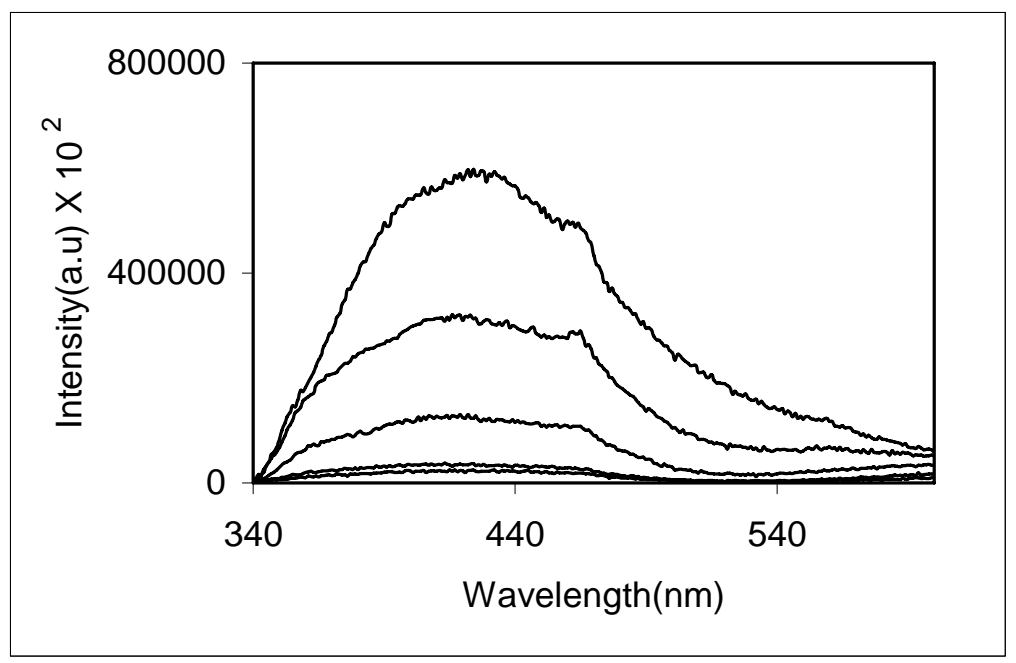

Figure 6. Emission spectra taken in aqueous medium for (a) free 6-MP (5 mM) and (b-e) for the adsorbed species on gold nanoparticles. The concentration of gold solution is varied $\left(0.5 \mathrm{~cm}^{3}-2\right.$ $\mathrm{cm}^{3}$ of $1 \mathrm{mM}$ gold solution), but the analysis time is kept constant (2 minutes) 
Page 19 of 28

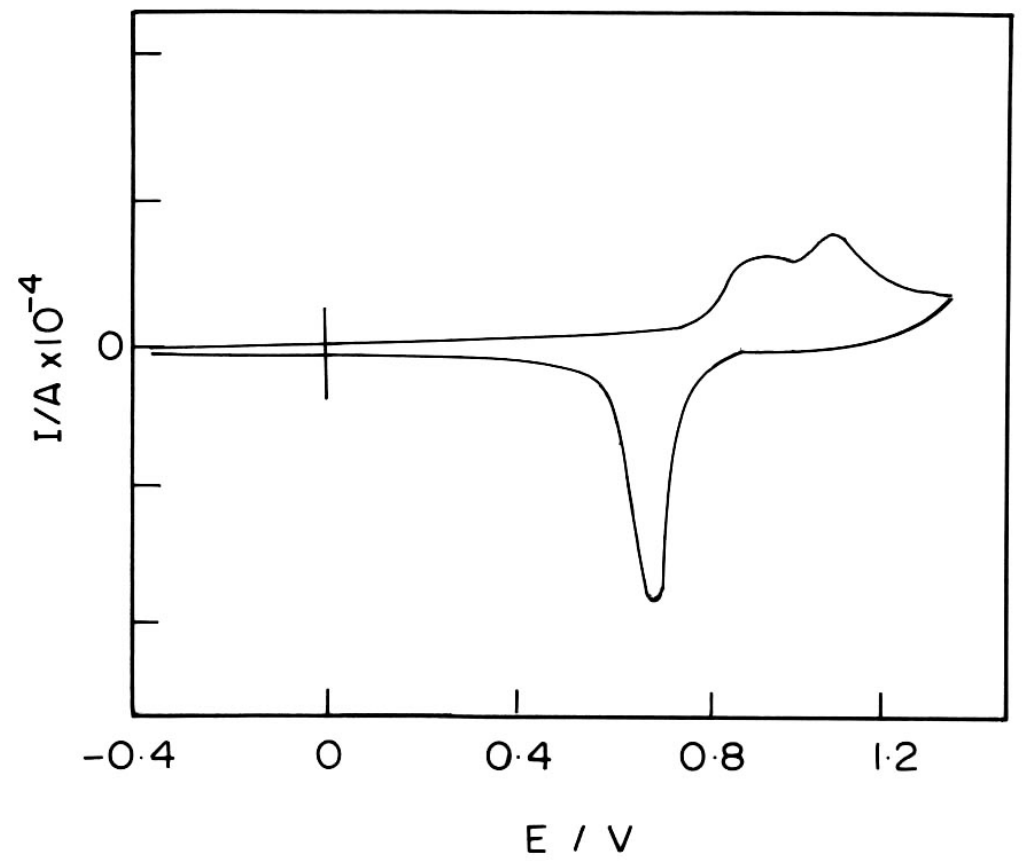

(a)

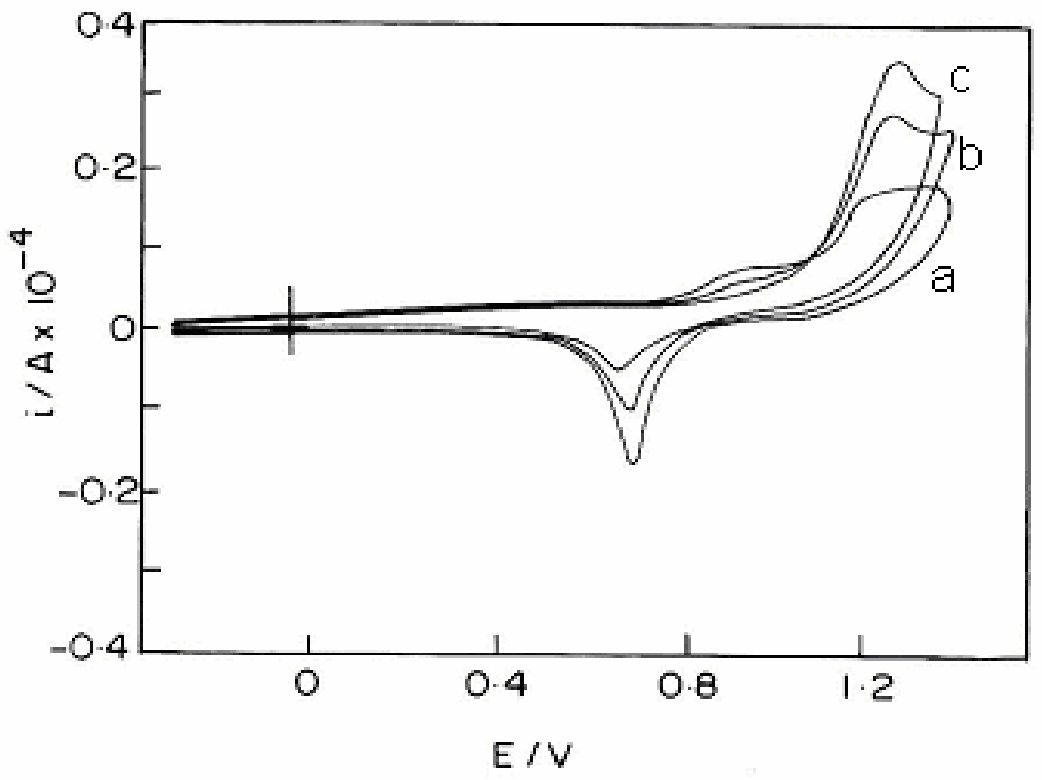

(b) 
Page 20 of 28

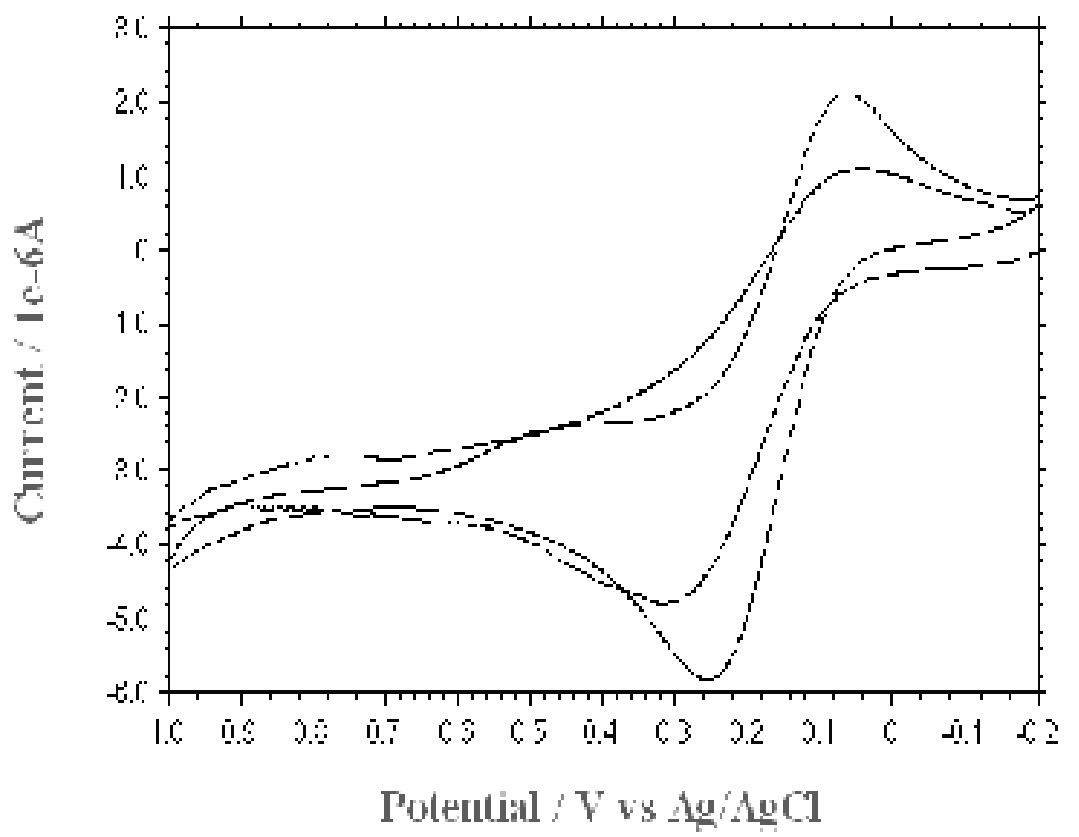

(c)

Figure 7: Cyclic voltammograms of a gold nanoparticle-modified electrode (a) in the absence of 6-MP in $0.01 \mathrm{M} \mathrm{HClO}_{4}$. M, (b) in the presence of different concentrations of 6-MP in $0.01 \mathrm{M} \mathrm{HClO}_{4}$. (a) 50 (b) 100 and (c) $150 \mu \mathrm{M}$. The scan rate is maintained at $0.02 \mathrm{~V} \mathrm{~s}^{-1}$. and (c) in $1 \mathrm{mM} \mathrm{K}_{4} \mathrm{Fe}(\mathrm{CN})_{6}$ at a scan rate of $10 \mathrm{mV} \mathrm{s}^{-1}$. 
Page 21 of 28

(a)

(c) 
Page 22 of 28

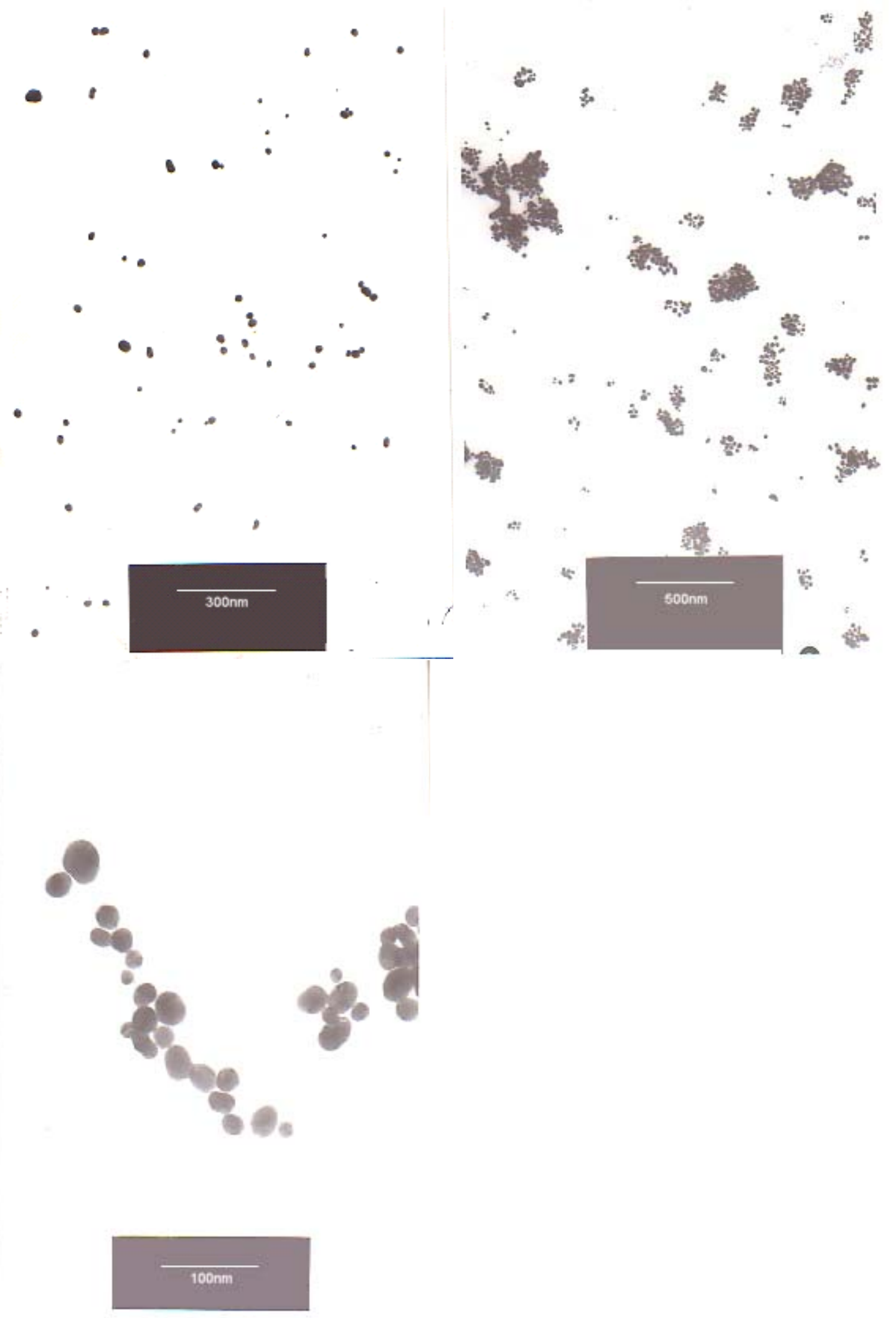


Page 23 of 28

Figure 8 Transmission electron micrographs of 6-MP-covered gold nanoparticles of average diameter $20 \mathrm{~nm}$. The samples were prepared from an aqueous solution: (a) gold nano particle; (b) 6-MP-covered gold nanoparticles; (c) expanded portion of 6-MP covered gold nanoparticles 
Page 24 of 28
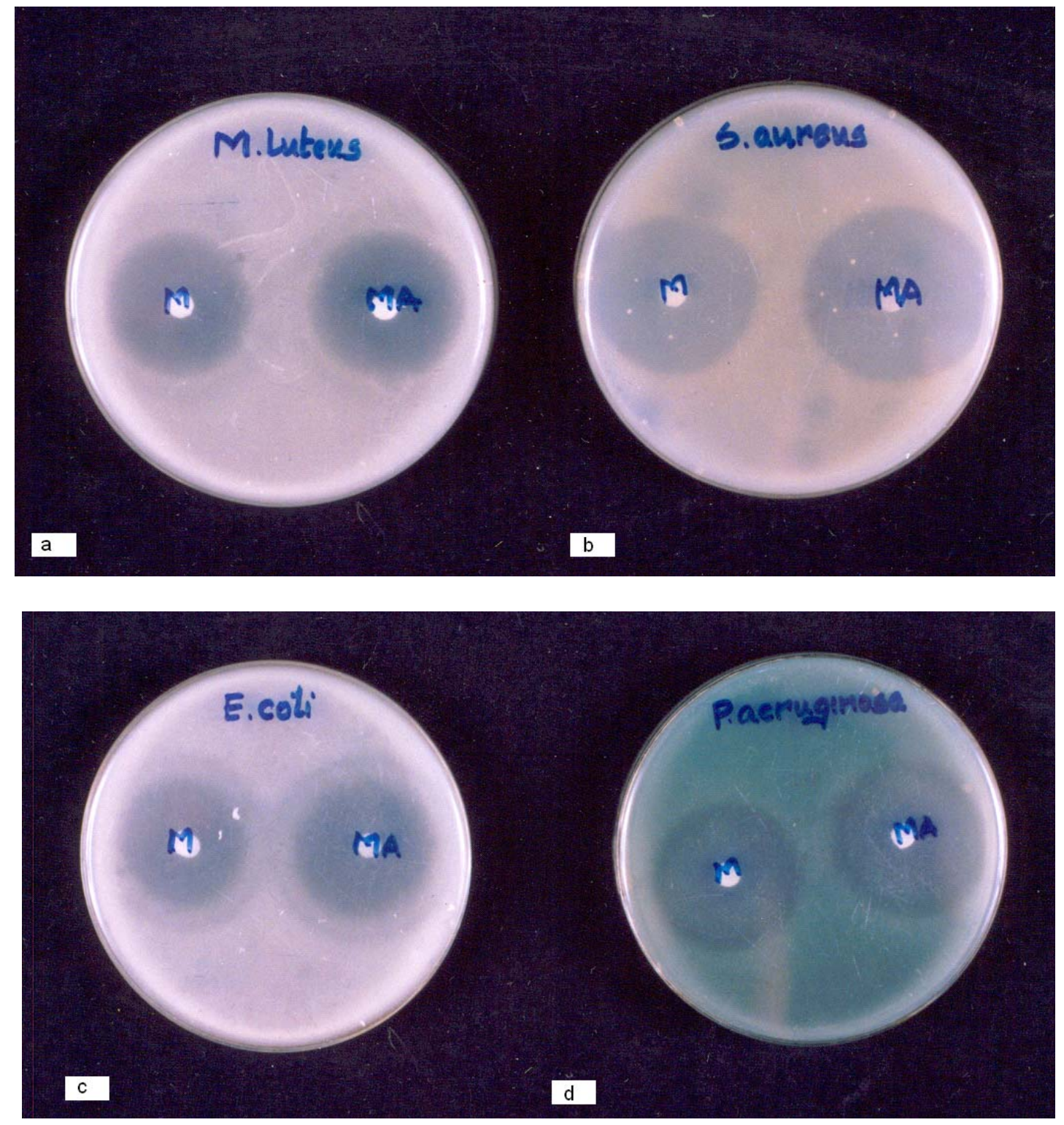

Figure 9 Antibacterial activity of 6-MP and 6-MP-covered gold. (a) Micrococcus luteus (b) Staphylococcus luteus (c) E-Coli (d) Staphylococcus aureus 
Page 25 of 28

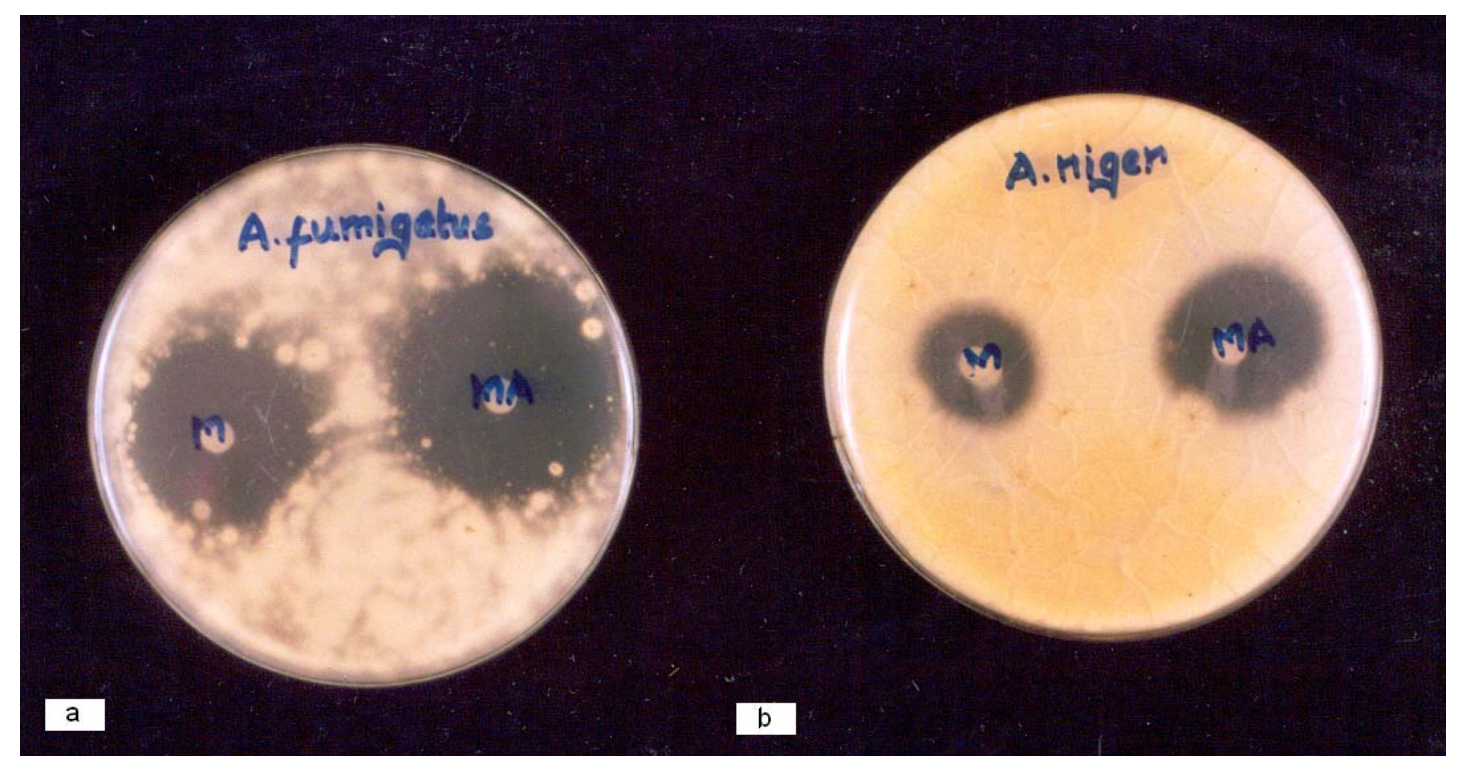

Figure 10. Antifungal activities of 6-MP and 6-MP-covered gold (a) Aspergillus fumigatus (b) Aspergillus niger 
Page 26 of 28
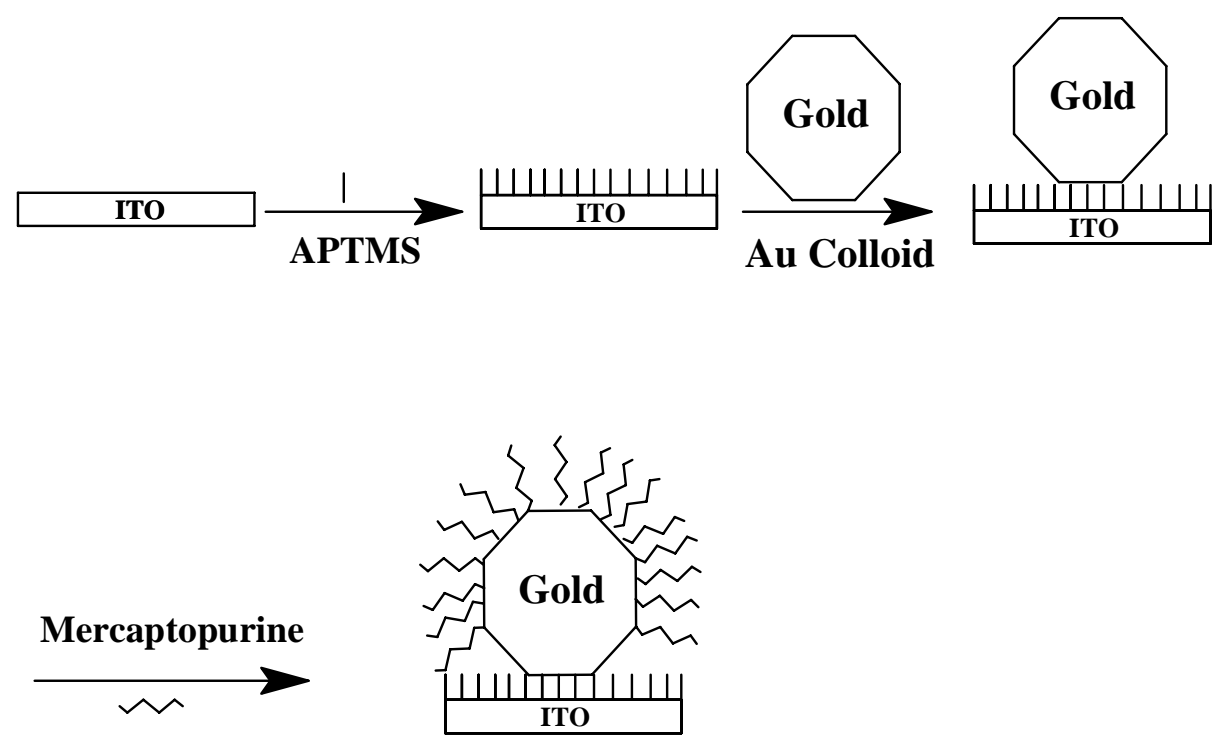

Scheme1. Aggregation of 6-MP on Gold nanoparticles 
Page 27 of 28

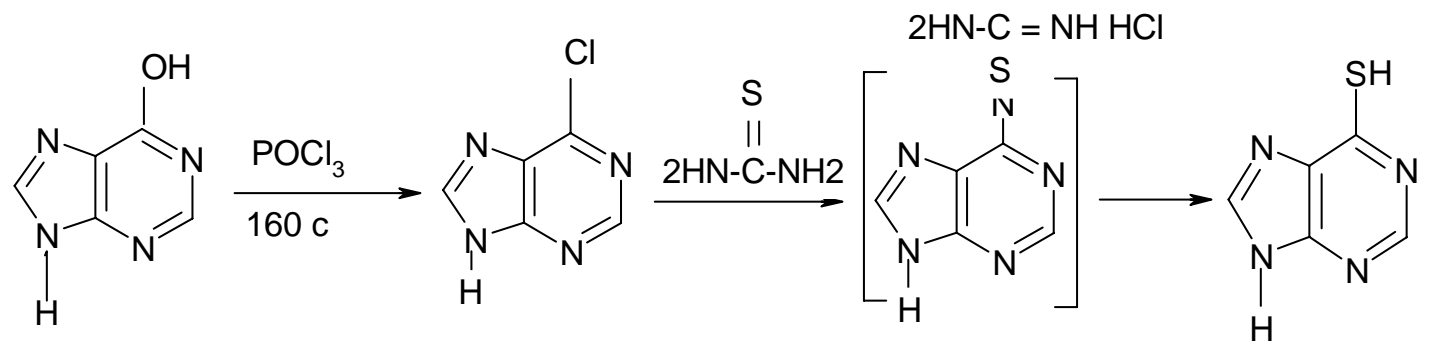

Scheme 2. Synthesis of 6-mercaptopurine (6-MP) 
Page 28 of 28

Table 1 Antibacterial activity of 6-mercaptopurine (6-MP)

\begin{tabular}{|c|c|c|c|}
\hline \multirow{2}{*}{ Micro organisms } & \multirow{2}{*}{ Nature of organism } & \multicolumn{2}{|c|}{ Levels of Zone of inhibition } \\
\cline { 3 - 4 } & & Pure 6-MP & $\begin{array}{c}\text { 6-MP-coated gold } \\
\text { nanoparticles }\end{array}$ \\
\hline Micrococcus luteus & Gramme Positive & 41 & 45 \\
\hline Staphylococcus aureus & Gramme Positive & 49 & 57 \\
\hline Pseudomonas aeruginosa & Gramme Negative & 51 & 63 \\
\hline E-Coli & Gramme Negative & 60 & 72 \\
\hline
\end{tabular}

Table 2 Antifungal activity of 6-mercaptopurine (6-MP)

\begin{tabular}{|c|c|c|}
\hline \multirow{2}{*}{ Fungal Organisms } & \multicolumn{2}{|c|}{ Levels of Zone of inhibition } \\
\cline { 2 - 3 } & Pure 6-MP & 6-MP-coated gold nanoparticles \\
\hline Aspergillus fumigatus & 45 & 59 \\
\hline Aspergillus niger & 32 & 37 \\
\hline
\end{tabular}

